\title{
Análise e monitoramento de pontos críticos no abate de frangos utilizando indicadores microbiológicos
}

\author{
Analysis and monitoring of critical points in the poultry slaughter using microbiological indicators
}

\author{
Augusto César Almeida Rodrigues ${ }^{\mathrm{I}}$ Paulo Sérgio de Arruda Pinto II* \\ Maria Cristina Dantas Vanetti ${ }^{\mathrm{II}}$ Paula Dias Bevilacqua ${ }^{\mathrm{II}}$ Mayara Souza Pinto ${ }^{\mathrm{I}}$ \\ Luís Augusto Nero ${ }^{\text {II }}$
}

\section{RESUMO}

A presença de microrganismos indicadores de contaminação na linha de abate de frangos foi determinada visando identificar os possíveis pontos de controle e oferecer uma opção para o monitoramento ou a verificação pelo sistema "Análise de Perigos e Pontos Críticos de Controle" (APPCC). A contaminação superficial das carcaças foi determinada pela enumeração de microrganismos aeróbios mesófilos, coliformes totais, coliformes termotolerantes e de Escherichia coli nas seguintes fases de abate: A - antes do primeiro chuveiro de higienização, $B$ - após o primeiro chuveiro, $C$ - após a evisceração manual, D - após o chuveiro de lavagem final e E - na saída do pré-resfriamento. Não houve diferença significativa $(P<0,05)$ entre as médias de mesófilos, coliformes totais e termotolerantes, entre as fases A, $B, C$ e D. Entretanto, as médias obtidas para esses microrganismos indicadores na fase $E$ (pré-resfriamento) foram significativamente menores. Não houve diferença significativa entre as médias de Escherichia coli nas cinco fases. As chances de contaminação (Razão de Chances) por mesófilos foram maiores na fase A e por coliformes na fase $C$. Entre os parâmetros analisados, os níveis de contaminação por mesófilos, coliformes totais e termotolerantes foram os mais indicados para monitoramento e verificação de um plano APPCC no abate de aves. Os resultados obtidos indicaram que a fase de pré-resfriamento pode ser considerada um importante ponto crítico de controle, uma vez que foi capaz de reduzir a contaminação microbiológica de forma significativa.

Palavras-chave: mesófilos, coliformes, abate de frangos, APPCC.

\section{ABSTRACT}

Hygiene indicator microorganisms in a poultry slaughter was evaluated during the processing in order to identify potential critical control points and allow options for monitoring or verification by Hazard Analysis Critical Control Point (HACCP) system. Microbiological superficial contamination of chicken carcasses was establish by the enumeration of mesophilic aerobes, total coliforms, thermotolerant coliforms and Escherichia coli in the following steps of processing: A - before the first hygienic shower, $B$ after the first hygienic shower, $C$ - after manual evisceration, $D$ - after final washing shower, and E - after the chiller tank. The mean counts of mesophilic aerobes, total and thermotolerant coliforms was not significantly different $(P<0.05)$ in the steps $A, B, C$ and $D$. However, the mean values of these microorganisms in step E (after chilling) was significantly lower when compared to the one obtained in the other steps. The mean counts of Escherichia coli were not significantly different, independently of the processing step analyzed. The chances of contamination were estimated by Odds Ration, and it was observed that chances were higher in the step A for mesophilic aerobes, and in the step $C$ for coliforms. Considering the analyzed parameters, the levels of contamination by mesophilic aerobes, total and thermotolerant coliforms were the most suitable for monitoring and verification of a HACCP system in a poultry processing plant. The obtained results indicate that the chilling can be considered as an important critical control point, once this procedure was able to reduce significantly the microbiological contamination.

Key words: mesophilic aerobes, coliforms, poultry slaughter, HACCP.

\section{INTRODUÇÃO}

A abertura do mercado externo para a carne brasileira tem exercido grande influência no aprimoramento dos sistemas de controle da sua qualidade em toda a cadeia produtiva, a começar pelo

IMinistério da Agricultura Pecuária e Abastecimento, Representação Regional, Viçosa, MG, Brasil.

IIDepartamento de Veterinária, Universidade Federal de Viçosa (UFV), 36570-000, Viçosa, MG, Brasil. E-mail: pintopsa@ufv.br.

* Autor para correspondência.

IIIDepartamento de Microbiologia, UFV, Viçosa, MG, Brasil 
setor mais organizado, o industrial. Nesse contexto, o sistema de Análise de Perigos e Pontos Críticos de Controle (APPCC) constitui uma ferramenta importante e passível de se ser aplicada, inclusive no abate de frangos (CATES et al., 2001). Este tem o objetivo de avaliar de forma contínua e sistemática a qualidade do produto, tendo em vista não apenas o aspecto final, mas também as diferentes fases do processo produtivo.

O APPCC foi desenvolvido para controlar perigos, entre os quais, os microbiológicos, principalmente os microrganismos patogênicos ao ser humano, seja monitorando a sua presença ou a de indicadores de qualidade em diferentes fases do abate, sobretudo nos pontos críticos de controle (HOGUE et al., 1998). Entretanto, considerando a necessidade de analisar e monitorar estes pontos, a utilização de organismos patogênicos, na prática, é difícil, onerosa e demorada, sendo importante ou mais conveniente, a pesquisa dos indicadores microbiológicos. Estes indicadores permitem aferir adequadamente o sistema APPCC, de forma de garantir a segurança sanitária do processo de abate (ICMSF, 1997).

Apesar de a maioria dos microrganismos identificados não apresentar potencial patogênico para humanos, os agentes indicadores ou seus produtos metabólicos são utilizados para avaliar a qualidade microbiológica e a sanidade do produto. A sua presença sugere a ocorrência de contaminação microbiana com possível presença de patógenos ou deterioradores potenciais do alimento, indicando condições sanitárias inadequadas de manipulação, processamento, produção ou armazenamento (ICMSF, 1982).

Em alimentos processados, a presença de níveis elevados de microrganismos aeróbios mesófilos e de bactérias do grupo coliforme indica tratamento inadequado e/ou, contaminação pós-processamento ocorrida, principalmente, pelo contato do produto acabado com matérias-primas e equipamentos sujos ou falta de higiene na manipulação. (RASZL et al., 2001).

$\mathrm{Na}$ avaliação da qualidade de aves, os indicadores microbiológicos vêm sendo empregados principalmente na análise do produto final, mas também vêm sendo recomendados para o processo de abate (AVENS et al., 2002; CARVALHO et al., 2002; CARDOSO et al., 2005).

Neste sentido, o presente trabalho teve como objetivos avaliar a contaminação superficial de carcaças de frango por microrganismos aeróbios mesófilos, coliformes totais, coliformes termotolerantes e Escherichia coli em diferentes fases do processo de abate, como alternativa de métodos analíticos para o monitoramento ou a verificação do processo de abate de aves, e analisar os pontos de controle em estabelecimentos de abate de frangos.

\section{MATERIAL E MÉTODOS}

Esta pesquisa foi desenvolvida em um abatedouro de aves, com capacidade de abate de 165.000 animais por dia, que abastece os mercados nacional e internacional. Nesse estabelecimento, o Serviço de Inspeção Federal (SIF) exerce a supervisão sanitária do abate com monitoramento de vários parâmetros e critérios previstos na Portaria Ministerial no-210 (BRASIL, 1998). Parâmetros como o teor de cloro e a temperatura da água de pré-resfriamento, a temperatura da carcaça e a renovação desta nos tanques de pré-resfriamento são fiscalizados pelo SIF. Assim, controlou-se durante a pesquisa o teor de cloro residual livre, que se manteve entre $0,5 \mathrm{mg} \mathrm{L}^{-1}$ e $1,0 \mathrm{mg}$ $\mathrm{L}^{-1}$ na água de abastecimento utilizada nos chuveiros de lavagem de carcaça e 3,0mg L $\mathrm{m}^{-1}$ a 4,0mg L $\mathrm{m}^{-1}$ na água dos tanques de pré-resfriamento. A renovação de água nos tanques de pré-resfriamento manteve-se em torno de $1,5 \mathrm{~L}$ carcaça $^{-1}$ no primeiro estágio e $1,0 \mathrm{~L}$ carcaça $^{-1}$ no segundo estágio e a temperatura da água no ponto de entrada da carcaça de $16^{\circ} \mathrm{C}$ e $4^{\circ} \mathrm{C}$, respectivamente. A temperatura das carcaças na saída do sistema de pré-resfriamento variou entre $5^{\circ} \mathrm{C} \mathrm{e} 10^{\circ} \mathrm{C}$.

Ao longo do processo de abate, foram analisadas 26 amostras para a contagem de mesófilos e 25 para coliformes. Cada amostra foi composta de cinco carcaças selecionadas ao acaso e analisadas separadamente por cada fase de abate, perfazendo um total de 130 unidades amostrais (125 para coliformes), todas obtidas na área limpa da sala de matança, conforme a localização distribuída nos seguintes pontos: Fase A - antes do chuveiro de higienização, na entrada da área limpa (após a depenagem); B - após o primeiro chuveiro de lavagem; C - após a evisceração manual; D - após o chuveiro de lavagem final; e E - na saída do pré-resfriamento. Para cada unidade amostral, foram coletados esfregaços superficiais equivalentes a $50 \mathrm{~cm}^{2}$ da pele, usando esponjas esterilizadas (polietileno sem antimicrobiano) em duas áreas delimitadas em $25 \mathrm{~cm}^{2}$ (peito e dorso da carcaça). Foi utilizada uma esponja para cada área. Após a coleta, as duas esponjas foram transferidas para sacos plásticos estéreis e foram, em seguida, homogeneizadas em 50mL de água peptonada tamponada a 0,1\%, durante um minuto, em homogeneizador peristáltico (Stomacher 400, Seward, West Sussex, UK).

A contagem padrão de Aeróbios Mesófilos (AM) foi realizada pela metodologia descrita por DOWNES \& ITO (2001) a partir de diluições decimais seriadas de $10^{-1}$ até $10^{-5}$ do material homogeneizado. Aa amostras foram plaqueadas em ágar padrão de contagem (PCA) e incubadas por 48 horas a $35^{\circ} \mathrm{C}$. A 
contagem visual das unidades formadoras de colônias (UFC) foi expressa em UFC $\mathrm{cm}^{-2}$ e os resultados foram mostrados nas tabelas em $\log _{10}$.

O Número Mais Provável (NMP) de coliformes totais (CT), de coliformes termotolerantes (CTT) e de $\boldsymbol{E}$. coli (EC) foi determinado segundo DOWNES \& ITO (2001), a partir das diluições $10^{-1}, 10^{-}$ ${ }^{2}$ e $10^{-3}$ do homogenato, para o ponto E, e $10^{-2}, 10^{-3}$ e $10^{-4}$ para os pontos A, B, C e D. O NMP foi interpretado

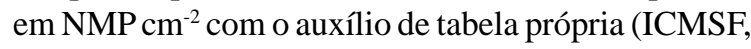
1982).

O teste presuntivo de coliformes totais foi realizado, em triplicata, em caldo lauril sulfato triptose (LST) com tubos de Duhran, com incubação a $35^{\circ} \mathrm{C}$ por 24 e 48 horas. Após esse período, alíquotas de caldo LST, onde se constatou crescimento e formação de gás, foram transferidas com o auxílio de alça de platina para tubos com caldo verde brilhante bile $2 \%$, em triplicata, e incubados a $35^{\circ} \mathrm{C}$ por 24 e 48 horas. Os tubos de BRILA com crescimento e produção de gás foram considerados positivos para a presença de coliformes totais.

Para a confirmação da presença de coliformes termotolerantes, alíquotas do Caldo LST, onde se constatou crescimento e formação de gás, foram transferidas com o auxílio de alça de platina para tubos com caldo Escherichia coli, em triplicata, com tubos de Duhran, e incubados em banho-maria a $44,5^{\circ} \mathrm{C}$ por 24 horas. Também foram incubados dois tubos contendo culturas padrão de $\boldsymbol{E}$. coli ou Enterobacter aerogenes, como controles positivo e negativo, respectivamente. Os tubos com crescimento e produção de gás foram considerados positivos para a presença de coliformes termotolerantes.

Para a análise de $\boldsymbol{E}$. coli, foi semeada uma alçada dos tubos positivos do caldo EC para placas contendo ágar eosina azul de metileno, e incubadas a $35^{\circ} \mathrm{C}$ por 24 horas. Das colônias típicas formadas, uma foi transferida para ágar PCA inclinado, incubado a $35^{\circ} \mathrm{C}$ por 24 horas. Em seguida, foram realizadas a análise morfo-tintorial (Gram) e as provas bioquímicas do IMViC (Indol, Voges-Proskauer, vermelho de metila e citrato).

Os resultados de AM, CT, CTT e EC foram submetidos à análise não-paramétrica pelo teste de Kruskal-Wallis ao nível de significância de 5\% (UFV, 2005), para a comparação das médias de contaminação dos diferentes indicadores microbiológicos nas diferentes fases de abate.

As chances de contaminação por cada indicador microbiológico entre as diferentes fases do abate foram quantificadas por meio do cálculo da razão de chances (“Odds Ratio” - OR) e respectivo intervalo de confiança a 5\% de significância, utilizando o programa Epi Info, versão 3.3.2 (WHO / CDC, 2005). Visto que a legislação brasileira não prevê padrões para os indicadores microbiológicos estudados em carcaças de frangos pré-resfriadas (BRASIL, 2001), foi estabelecido para o cálculo da OR um limite de referência para os resultados de cada indicador microbiológico, calculado como a média da carga microbiana das 130 unidades amostrais analisadas para AM e 125 CT, CTT e EC. Para a elaboração da tabela de contingência dois por dois e subseqüente cálculo da OR, foram consideradas indesejáveis do ponto de vista de controle de qualidade as freqüências de indicadores acima do referido limite e desejáveis as abaixo.

\section{RESULTADOS E DISCUSSÃO}

As médias de AM, CT, CTT e EC são apresentadas na tabela 1 . Verifica-se que não houve diferença estatística significativa $(\mathrm{P}<0,05)$ entre as fases A, B, C e D para AM, CT e CTT. Por outro lado, a fase $\mathrm{E}$ (pré-resfriamento) revelou uma queda significativa desses indicadores microbiológicos, quando comparada com as quatro fases mencionadas, com exceção de EC. Contudo, o menor valor da freqüência deste indicador também ocorreu na fase E. Índices semelhantes de contaminação e redução de NMP de coliformes totais e termotolerantes após a passagem da carcaça pelo pré-resfriamento foram relatadas anteriormente (SOARES et al., 2002).

A redução significativa da contaminação de carcaças de frangos detectada para a fase E se deve ao efeito do processo de pré-resfriamento por imersão em água clorada (3 a $4 \mathrm{mg} \mathrm{L}^{-1}$ de cloro residual livre) e refrigerada, que atua como o principal fator redutor da contaminação microbiana superficial (BOLDER, 1997; ALLEN et al., 2000). Desse modo essa fase é o principal alvo para o controle microbiológico da carcaça dentre os aqui avaliados.

Os chuveiros de lavagem das carcaças instalados, entre as fases A e B e entre as fases C e D, não exerceram efeito significativo na redução de AM, CT, CTT e EC. Estes resultados demonstraram a necessidade de outros estudos para avaliar a real eficácia dos chuveiros de lavagem de carcaça, sobretudo a possível influência do ajuste do seu funcionamento, com pressão e direcionamento adequados dos jatos d'água durante o processo de abate. A contagem de mesófilos é significativamente reduzida quando a carcaça é submetida à água sob pressão(BOLDER, 1997).

Considerando-se a freqüência de amostras positivas para os diferentes indicadores 
Tabela 1 - Médias de aeróbios mesófilos, coliformes totais, coliformes termotolerantes e Escherichia coli em carcaças de frango por fase de abate $\left(\log _{10}\right.$ UFC ou NMP $\left.\mathrm{cm}^{-2}\right)$.

\begin{tabular}{|c|c|c|c|c|}
\hline \multirow{2}{*}{ Fase de abate $^{(1)}$} & \multicolumn{4}{|c|}{ 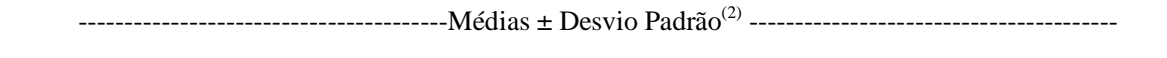 } \\
\hline & Aeróbios mesófilos & Coliformes totais & Coliformes termotolerantes & Escherichia coli \\
\hline A & $4,1 \pm 0,5^{\mathrm{a}}$ & $3,1 \pm 0,6^{\mathrm{a}}$ & $3,0 \pm 0,6^{a}$ & $0,8 \pm 1,2^{\mathrm{a}}$ \\
\hline B & $3,9 \pm 0,5^{\mathrm{a}}$ & $2,9 \pm 0,7^{a}$ & $2,7 \pm 0,8^{\mathrm{a}}$ & $0,5 \pm 1,0^{\mathrm{a}}$ \\
\hline $\mathrm{C}$ & $3,8 \pm 0,6^{\mathrm{a}}$ & $3,2 \pm 0,4^{\mathrm{a}}$ & $3,0 \pm 0,6^{a}$ & $0,7 \pm 1,2^{\mathrm{a}}$ \\
\hline $\mathrm{D}$ & $3,7 \pm 0,4^{a}$ & $3,2 \pm 0,6^{a}$ & $3,0 \pm 0,6^{\mathrm{a}}$ & $0,6 \pm 0,9^{a}$ \\
\hline $\mathrm{E}$ & $1,7 \pm 1,1^{\mathrm{b}}$ & $0,7 \pm 0,8^{\mathrm{b}}$ & $0,7 \pm 0,8^{b}$ & $0,1 \pm 0,4^{\mathrm{a}}$ \\
\hline
\end{tabular}

NOTAS: (1) A: antes do chuveiro de higienização na entrada da área limpa (após a depenagem); B: após o primeiro chuveiro de lavagem; C: após a evisceração manual; D: após o chuveiro de lavagem final; E: na saída do pré-resfriamento. (2) Médias seguidas de mesma letra, na mesma coluna não diferem estatisticamente ao nível de 5\% de significância pelo teste de Kruskal-Wallis.

microbiológicos foi estimado o risco de contaminação a partir do cálculo da OR baseada nos limites de referências que foram 3,44, 2,60, 2,49 e 0,56 para AM, CT, CTT e EC, respectivamente. Para avaliar o risco microbiológico e quantificá-lo, adotou-se, como categoria base, a fase do abate onde ocorreu menor porcentagem de positivos, a qual foi arbitrariamente identificada com uma OR $=1,00$. Para todos os indicadores esta fase de abate coincidiu como a fase $\mathrm{E}$ (Tabela 2).

Apenas para EC não houve diferença estatisticamente significante entre as freqüências de amostras fora do limite, por isso não foi calculada a OR para este parâmetro. As freqüências de carcaças de frangos contaminadas por $\boldsymbol{E}$. coli acima do limite de referência foram de $40 \%$, 28\%, 32\%, 36\% e 16\%, respectivamente, para as fases de abate A, B, C, D e E.

A chance de contaminação da carcaça com aeróbios mesófilos foi mais elevada até a entrada da área limpa da sala de abate (fase A), com uma OR de 144,00 (Tabela 2), comparando com o pré-resfriamento (fase E). A maior chance de contaminação por mesófilos nas fases A e B pode estar associada a alguns fatores como a depenagem, conforme relatou VIEIRA \& TEIXEIRA (1997), e à ineficiência do chuveiro de

Tabela 2 - Freqüência de aeróbios mesófilos, coliformes totais, coliformes termotolerantes acima do limite de referência e “Odds Ratio" (OR) para os fatores de risco de contaminação em carcaças de frangos entre diferentes fases de abate.

\begin{tabular}{|c|c|c|c|c|}
\hline Microrganismo & Fase de abate & Freqüência (\%) & $\mathrm{p}^{(1)}$ & OR (IC 95\%) $)^{(2)}$ \\
\hline \multirow{5}{*}{ Aeróbios mesófilos } & A & $24(92,3)$ & 0,0000000 & $144,0(14,8<\mathrm{OR}<2446,2)$ \\
\hline & B & $23(88,5)$ & 0,0000000 & $92,0(11,4<\mathrm{OR}<1089,7)$ \\
\hline & $\mathrm{C}$ & $19(73,1)$ & 0,0000020 & $32,6(5,2<\mathrm{OR}<268,1)$ \\
\hline & $\mathrm{D}$ & $16(61,5)$ & 0,0000500 & $19,2(3,2<\mathrm{OR}<48,9)$ \\
\hline & $\mathrm{E}$ & $2(7,7)$ & & 1,0 \\
\hline \multirow{5}{*}{ Coliformes totais } & A & $19(76,0)$ & 0,0000003 & $76,0(7,6<\mathrm{OR}<1863,1)$ \\
\hline & B & $18(72,0)$ & 0,0000009 & $61,7(6,4<\mathrm{OR}<1479,3)$ \\
\hline & $\mathrm{C}$ & $23(92,0)$ & 0,0000000 & $276,0(18,9<\mathrm{OR}<10379,2)$ \\
\hline & $\mathrm{D}$ & $22(88,0)$ & 0,0000000 & $176,0(14,4<\mathrm{OR}<5210,3)$ \\
\hline & $\mathrm{E}$ & $0(0,0)$ & - & 1,0 \\
\hline \multirow{5}{*}{$\begin{array}{l}\text { Coliformes } \\
\text { termotolerantes }\end{array}$} & A & $18(72,0)$ & 0,0000009 & $61,7(6,4<\mathrm{OR}<1476,3)$ \\
\hline & B & $14(56,0)$ & 0,0000714 & $30,6(3,4<\mathrm{OR}<704,2)$ \\
\hline & $\mathrm{C}$ & $22(88,0)$ & 0,0000000 & $176,0(14,4<\mathrm{OR}<5210,3)$ \\
\hline & $\mathrm{D}$ & $20(80,0)$ & 0,0000001 & $96,0(9,2<\mathrm{OR}<2437,4)$ \\
\hline & $\mathrm{E}$ & $0(0,0)$ & - & 1,0 \\
\hline
\end{tabular}

NOTAS: (1) valor de p para o teste do Qui-quadrado; (2) Intervalo de confiança 95\%. 
lavagem anterior da carcaça, conforme discutido anteriormente.

Os resultados de OR para coliformes mostram que, apesar de as médias de contaminação entre as fases A, B, C e D não diferirem estatisticamente, há diferenças na chance de encontrar carcaças contaminadas entre essas fases (Tabela 2).

A fase C, geralmente responsável por acrescentar microrganismos de origem fecal à superfície da carcaça (ALMEIDA \& SILVA, 1992), aparentemente não foi capaz de promover aumento significativo da presença média dos mesmos nas carcaças analisadas neste estudo. Isso se deve ao fato de as médias de contaminação entre as fases A, B, C e D não diferirem estatisticamente (Tabela 1). Contudo, a freqüência de amostras positivas para indicadores de origem fecal apresentou maior probabilidade de ocorrer nessa etapa, com OR de 276,0 e 176,0, para CT e CTT, respectivamente (Tabela 2 ).

A maior OR para coliformes totais e termotolerantes na fase $C$ pode ter sido influenciada pelo sistema de eventração, que é automático, não se adaptando às diferenças de tamanho das carcaças, promovendo, consequentemente, o rompimento das vísceras e o extravasamento do conteúdo intestinal, o que foi visualizado em algumas carcaças durante a coleta das amostras. Tal contaminação também poderá estar associada ao sistema de autolavagem dos equipamentos de eventração, que num primeiro momento pode auxiliar na lavagem da carcaça, mas pode disseminar eventual contaminação fecal em seguida, resultando num aumento de coliformes na carcaça (WALSH \& THAYER, 1993).

Analisando simultaneamente as OR das fases A e C para os diferentes indicadores microbiológicos, percebe-se que a microbiota mesofílica mais freqüente na fase A ficou parcialmente selecionada pela microbiota de origem fecal à medida que o processo de abate ultrapassou a fase de evisceração (C). Por sua vez a contaminação por coliformes se mostrou menos importante na fase A.

Desse modo, as operações de eventração e evisceração devem ser criteriosamente consideradas num plano APPCC de abate de frangos, devido à maior probabilidade de contaminação fecal nessa fase. Por isso, o rigoroso controle da higiene ambiental da respectiva área e, equipamentos e a minimização das ocorrências de rompimento de vísceras devem ser implementados para o sucesso do plano APPCC.

\section{CONCLUSÕES}

O número de mesófilos e de coliformes totais e termotolerantes foram os parâmetros mais indicados entre os estudados para monitoramento e verificação de um plano APPCC no abate de aves, pois sempre estiveram presentes nas fases selecionadas para o estudo e mostraram diferentes freqüências entre as fases pesquisadas.

O sistema de lavagem das carcaças não proporcionou higiene adequada das mesmas, provavelmente devido ao mau funcionamento dos chuveiros entre a entrada das carcaças na área limpa e o início de evisceração e entre o final da evisceração e entrada no sistema de pré-resfriamento. A fase de evisceração ficou evidenciada como uma operação de abate onde se consolida a contaminação fecal de carcaças de frango, merecendo atenção nos procedimentos de monitoramento e verificação dos planos APPCC, como ponto de controle. O préresfriamento é um importante ponto de controle que foi capaz de reduzir significativamente a contaminação bacteriana; esta fase também deve ser adequadamente monitorada, principalmente como um ponto crítico de controle, para garantir a qualidade microbiológica da carne do frango.

\section{REFERÊNCIAS}

ALLEN, V.M. et al. Hygiene aspects of modern poultry chilling. International Journal of Food Microbiology, v.58, p.3948, 2000

ALMEIDA, P.F.; SILVA, E.N. Estudos sobre o controle e disseminação bacteriana em carcaças de frangos de abatedouros industriais. Arquivo Brasileiro de Medicina Veterinária e Zootecnia, v.44, n.2, p.105-120, 1992.

AVENS, J.S. et al. Destruction of microorganisms on chicken carcasses by steam and boiling water immersion. Food Control, v.13, p.445-450, 2002.

BOLDER, N.M. Decontamination of meat and poultry carcasses. Trends in Food Science \& Technology, v.8, p.221227, 1997.

BRASIL, Ministério da Agricultura, Pecuária e Abastecimento. Portaria 210, de 10 de Novembro de 1998. Regulamento técnico de inspeção tecnológica e higiênico sanitária de carne de aves. Diário Oficial da União de 26/11/1998. seção 1. p.226. Brasil. 1998.

BRASIL, Ministério da Saúde, DINAL. Resolução - RDC n.12, de 2 de janeiro de 2001. Aprova o Regulamento técnico sobre padrões microbiológicos para alimentos, em seus anexos I e II. Diário Oficial da União de 10/01/2001. seção 1. Brasil. 2001.

CARDOSO, A.L.S.P. et al. Pesquisa de Salmonella spp., coliformes totais, coliformes fecais, mesófilos, em carcaças e cortes de frango. Higiene Alimentar, v.19, n.128, p.144150, 2005. 
CARVALHO, L.T. et al. Análise de perigos e pontos críticos de controle na linha de produção de frango inteiro congelado. Higiene Alimentar, v.16, n.95, p.34-42, 2002.

CATES, S.C. et al. Traditional versus hazard analisys and critical control point-based inspection: results from a poultry slaugther project. Journal of Food Protection, v.64, n.6, p.826-832, 2001.

DOWNES, F.P.; ITO, K. Compendium of methods for the microbiological examination of foods. 4.ed. Washington: American Public Health Association, 2001 . 676p.

HOGUE, A.T. et al. Pathogen reduction and hazard analisys and critical control point (HACCP) systems for meat and poultry. Veterinary Clinics of North America: Food Animal Practice, v.14, n.1, p.151-164, 1998.

INTERNATIONAL COMMISSION ON MICROBIOLOGICAL SPECIFICATIONS FOR FOODS - ICMSF. Microorganismos de los Alimentos 1 - Técnicas de análisis microbiológico. Zaragoza: Acríbia, 1982. 431p.

INTERNATIONAL COMMISSION ON MICROBIOLOGICAL SPECIFICATIONS FOR FOODS - ICMSF. APPCC na qualidade e segurança microbiológica de alimentos. São Paulo: Varela, 1997. 361p.
RASZL, S.M. et al. HACCP: instrumento essencial para a inocuidade de alimentos. Instituto Pan-Americano de Proteção de Alimentos, 2001. 333p.

SOARES, J. et al. Análise de pontos críticos no abate de frangos, através da utilização de indicadores microbiológicos. Higiene Alimentar, v.16, n.95, p.53-61, 2002

UNIVERSIDADE FEDERAL DE VIÇOSA - UFV. Sistema de análise estatística e genética (SAEG 9.0). Central de processamento de dados. Viçosa, 2005.

VIEIRA, C.R.N.; TEIXEIRA, C.G. Condições higiênicosanitárias de carcaças resfriadas de frango comercializadas em Poços de Caldas-MG. Higiene Alimentar, v.11, n.48, p.3640, 1997.

WALSH, J.L.; THAYER, S.G. Evaluation of crosscontamination on automatic viscera removal equipment. Poultry Science, v.72, p.741-746, 1993.

WORLD HEALTH ORGANIZATION / CENTER OF PREVENTION AND CONTROL DISEASE - WHO/CDC). World processing database and statistics and program for public health (EpiInfo). WHO. Versão 3.3.2. Genebra, 2005. 